\title{
EFFECT AND MECHANISM OF PHOSPHORUS AND BORON ON CREEP DEFORMATION OF ALLOY 718
}

\author{
Wei-Di Cao and R. L. Kennedy \\ ALLVAC \\ An Allegheny Teledyne Company \\ Monroe, NC 28110 \\ USA
}

\begin{abstract}
The effect of $\mathrm{P}$ and $\mathrm{B}$ on creep deformation of alloy 718 was studied. It was found that both $\mathrm{P}$ and $\mathrm{B}$ increase the resistance to creep deformation with $\mathrm{P}$ being a much stronger strengthening element than $\mathrm{B}$. This result is in sharp contrast with the general belief that $\mathrm{P}$ is a detrimental element. Also of note is the strong synergistic effect of $\mathrm{P}$ and $\mathrm{B}$ revealed in alloy 718 . The combined addition of $\mathrm{P}$ and $\mathrm{B}$ generated an increase in stress rupture life time or a decrease in the creep rate much greater than the sum of the individual effect of $\mathrm{P}$ or $\mathrm{B}$. The $\mathrm{P}$ and $\mathrm{B}$ combined effect peaked at approximately $\mathrm{P}=0.022 \mathrm{wt} \%$ and $\mathrm{B}=0.012 \mathrm{wt} . \%$ and can be expressed as:

$$
t_{f}^{P, B}=t_{f 0}^{P, B} \exp \left\{-A_{P}\left(P-a_{P}\right)^{2}\right\} \exp \left\{-A_{B}\left(B-a_{B}\right)^{2}\right\}
$$

where $t_{f}^{P, B}$ is the stress rupture life, $t_{f 0}{ }^{P, B}$ the maximum stress rupture life, $A_{P}$ and $A_{B}$ are coefficients characterizing the rate of change for stress rupture life with changing $\mathrm{P}$ and $\mathrm{B}$ levels, $a_{p}=0.022 \%, a_{B}=0.012 \%$. The stress rupture life time can be increased $2-3$ times by controlling $\mathrm{P}$ and $\mathrm{B}$ to optimum levels.

The possible mechanisms of $\mathrm{P}, \mathrm{B}$ effects and $\mathrm{P}$ - $\mathrm{B}$ interaction were investigated by fractographic and TEM microstructural analyses. It seems that increased grain boundary cohesion by $\mathrm{P}$ and $\mathrm{B}$ additions and the direct interaction between $\mathrm{P}, \mathrm{B}$ atoms and dislocations and vacancies led to the improvement in creep deformation resistance observed in alloy 718 .
\end{abstract}

\section{Introduction}

Previously published work ${ }^{1,2}$ reported that increasing the $\mathrm{P}$ level exerts a significant, beneficial effect on stress rupture and creep properties of alloy 718 , and that there is a remarkable, synergistic interaction between $\mathrm{P}$ and $\mathrm{B}$. The stress rupture life time can be doubled by increasing the $\mathrm{P}$ level of commercial alloys from about $0.004-0.008 \%$ to $0.022 \%$. The stress rupture life can be further enhanced to $300 \%$ that of commercial alloys by increasing the B level to an optimum (about $0.012 \%$ ). These results imply an attractive possibility of developing an upgraded alloy

$$
\begin{aligned}
& \text { Superalloys 718, 625, } 706 \text { and Various Derivatives } \\
& \text { Edited by E.A. Loria } \\
& \text { The Minerals, Metals \& Materials Society, } 1997
\end{aligned}
$$


718 with much better creep properties but with little cost penalty. Such an alloy, named ALLVAC $718 \mathrm{ER}^{\mathrm{TM}}{ }^{3}$, is under evaluation at a full scale, production heat size.

Since there is almost no previous work published regarding the $\mathrm{P}$ effect and P-B interaction in $\mathrm{Ni}$-base alloys, systematic research work was conducted to fully characterize the $\mathrm{P}$ and $\mathrm{B}$ effect on processing and mechanical properties of alloy 718. At the same time, a CRADA project was initiated at Oak Ridge National Laboratory to explore the mechanisms of $\mathrm{P}$ and $\mathrm{B}$ effects in alloy 718 and other superalloys in detail. This paper will report the results of experimental work on $P$ and $B$ effects in improving stress rupture properties of alloy 718 and propose some tentative explanations on possible mechanisms responsible for the improvements observed.

\section{Experimental Procedures}

\section{Test Materials and Processing}

Fifty two test alloys were produced covering the matrix of P from $<0.001 \mathrm{wt} . \%$ to $0.035 \mathrm{wt} . \%$ and B from $<0.001 \mathrm{wt} . \%$ to $0.024 \mathrm{wt} . \%$ at two C levels of $<0.01 \mathrm{wt} . \%$ and $0.03 \mathrm{wt} . \%$ with all other elements being fixed at $18 \% \mathrm{Cr}-19.2 \% \mathrm{Fe}-2.9 \% \mathrm{Mo}-5.25 \% \mathrm{Nb}-0.95 \% \mathrm{Ti}-0.6 \% \mathrm{Al}-\mathrm{Bal}$. $\mathrm{Ni}$ (all in wt.\%). Two to three heats were made for some critical chemistries to check the repeatability of test results. For brevity, no tabulation of the chemistries of test alloys is presented.

All test alloys were vacuum induction melted (VIM) with a weight of $23 \mathrm{Kg}$ per heat and cast as $70 \mathrm{~mm}$ diameter electrodes. VIM electrodes were further refined by vacuum arc melting (VAR) to $100 \mathrm{~mm}$ diameter ingots. VIM/VAR ingots were homogenized for 16 hours at $1190^{\circ} \mathrm{C}$ and rolled to $15 \mathrm{~mm}$ diameter bars within the temperature range of $1040^{\circ} \mathrm{C}$ to $920^{\circ} \mathrm{C}$.

Specimen blanks for tensile and stress rupture tests were cut from as-rolled $15 \mathrm{~mm}$ bars and subjected to standard heat treatment; solutioned for 1 hour at $954^{\circ} \mathrm{C}$, air cooled and then aged for 8 hours at $718^{\circ} \mathrm{C}$, furnace cooled to $621^{\circ} \mathrm{C}$, held at $621^{\circ} \mathrm{C}$ for 8 hours, air cooled.

\section{$\underline{\text { Mechanical Tests }}$}

Room temperature and $649^{\circ} \mathrm{C}$ tensile tests were performed on all the test alloys to evaluate the effect of $\mathrm{P}$ and $\mathrm{B}$ levels on short term mechanical properties. Stress rupture tests were conducted in air at $649^{\circ} \mathrm{C}$ at two applied stress levels $(669 \mathrm{MPa}$ and $773 \mathrm{MPa})$ on all the test alloys to determine the effects of $\mathrm{P}$ and $\mathrm{B}$ levels on creep deformation.

Some interrupted tests were performed on a number of representative alloys with the aim of comparing the overaging behavior of alloys with different $\mathrm{P}$ and $\mathrm{B}$ levels and providing specimens having identical thermomechanical history (temperature, stress and time) for microstructure study.

\section{Microstructure and Fractography}

The microstructures of broken and interrupted stress rupture test specimens were exarnined by optical and scanning electron microscopy (SEM). The emphasis was placed on comparing the grain structure and phase morphology between different alloys before and after stress rupture testing to see if the observed improvements by $\mathrm{P}$ and $\mathrm{B}$ optimization could come from the 
changes in grain size or $\delta$ phase distribution or morphology. A detailed study on fine scale microstructurc was conducted at ORNL using high resolution transmission electron microscope, atom probe and Auger spectrum electron microscopy. These results will be published elsewhere.

The fracture surface of broken stress rupture specimens of all the test alloys was examined by SEM. The failure modes in different alloys were identified, and the fracture mode maps were constructed to show the effect of $\mathrm{P}$ and $\mathrm{B}$ on creep fracture mode of test alloys.

\section{Experimental Results}

\section{Tensile Properties}

The effect of $\mathrm{P}$ and $\mathrm{B}$ on room temperature and $649^{\circ} \mathrm{C}$ tensile properties was minor. As an example, the effect of $\mathrm{P}$ and $\mathrm{B}$ on room temperature tensile properties at $<0.005 \% \mathrm{C}$ is shown in Figure 1. It can be seen that there is virtually no effect of $P$ and $B$ on tensile yield stress and ductility of alloy 718 .

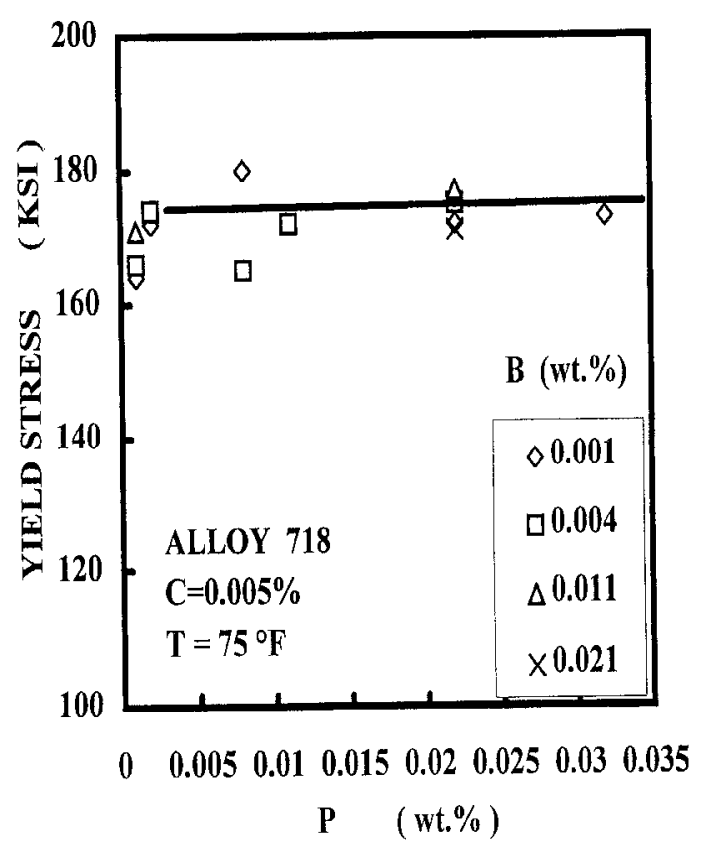

(a)

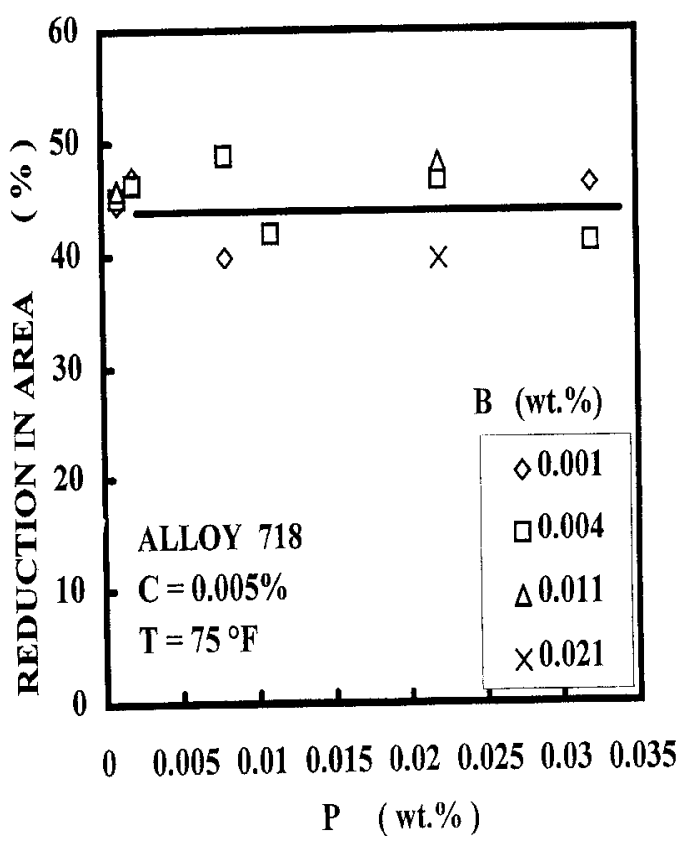

(b)

Figure 1 - Effect of P level on room temperature tensile properties of Alloy 718 with very low carbon (a) Yield stress and (b) Reduction in area.

\section{Stress Rupture Properties}

In order to demonstrate the effect of $\mathrm{P}$ and $\mathrm{B}$ levels on the stress rupture life of alloy 718 more clearly, a three-dimensional graph was constructed, as shown in Figure 2. It can be seen from this figure that a maximum of stress rupture life occurs at about $\mathrm{P} \%=0.022 \%$ and $\mathrm{B} \%=0.012 \%$. 


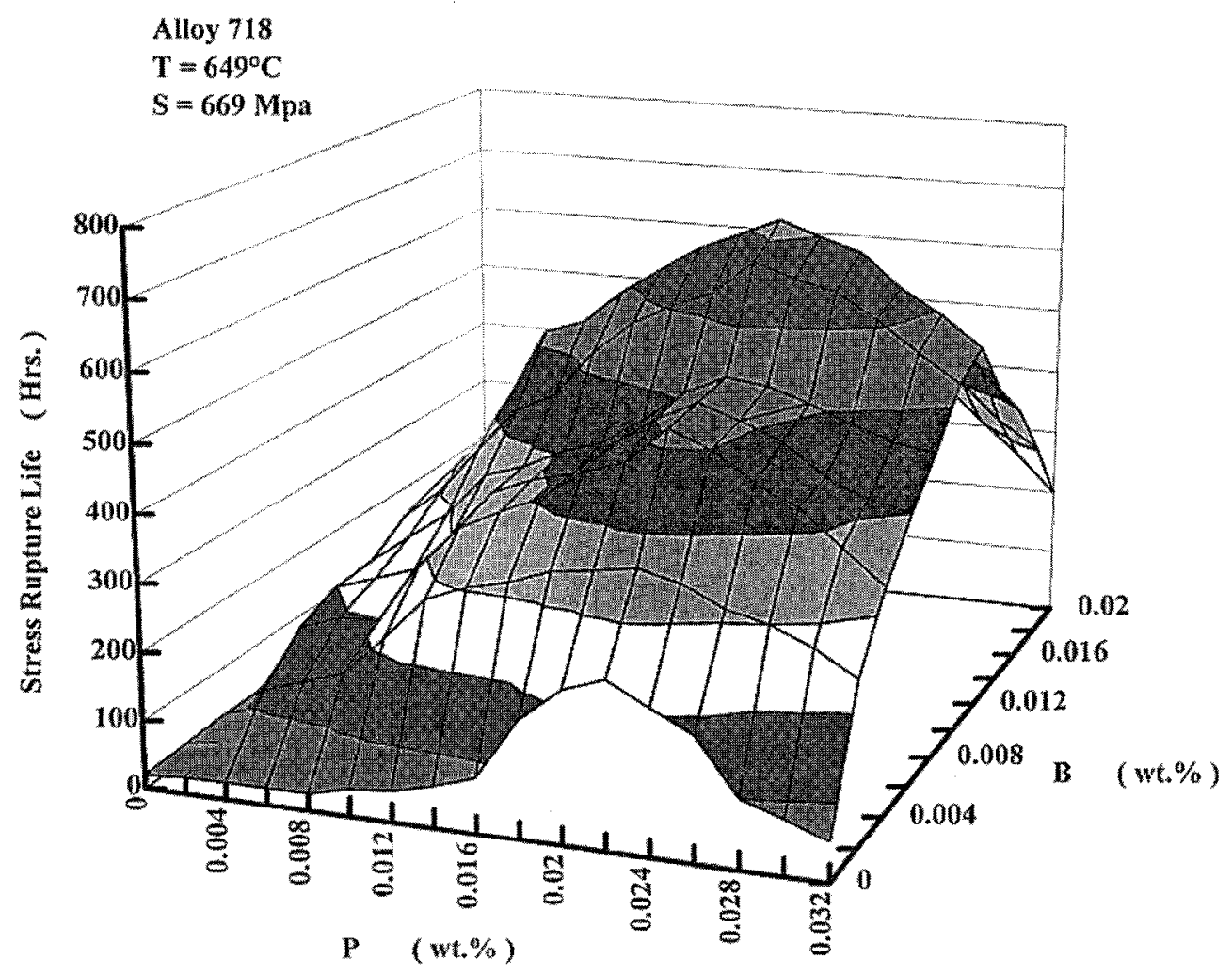

Figure 2 - Stress rupture life of Alloy 718 as a function of P and B Contents

Figures $3-5$ are several sections taken from Figure 2 to show the magnitude of improvements quantitatively. Figures 3 and 4 show the independent effect of $\mathrm{P}$ or B on stress rupture life. As shown in these two figures, increasing either the $\mathrm{P}$ or $\mathrm{B}$ level improves stress rupture life, but $\mathrm{P}$ has a stronger effect; compare the maximum life time of about $70 \mathrm{hrs}$ at $649 \mathrm{MPa}$ for $\mathrm{B}$ to about $275 \mathrm{hrs}$ at identical conditions for $\mathrm{P}$. The $\mathrm{B}$ effect reached a peak at a relatively lower level (about $0.01 \%$ ) and slowly decreased after that, but $\mathrm{P}$ has no significant effect until $0.008 \%$, and there is a sharp peak at about $0.022 \% \mathrm{P}$.

Figure 5 shows the effect of combined $\mathrm{P}$ and $\mathrm{B}$ additions on stress rupture life. These figures reveal an interesting synergistic effect between $\mathrm{P}$ and $\mathrm{B}$ additions; the result of the combined addition is greater than the sum of the effect of the individual elements at identical levels. For comparison, the stress rupture lives of some representative heats are listed in Table I.

Table I. Comparison of Stress Rupture I ives of Representative Test Alloys ( 0.03 wt.\% C)

\begin{tabular}{|c|c|c|c|c|c|c|c|}
\hline \multicolumn{2}{|c|}{ Test Alloys } & G988-2 & G500-1 & G726-1 & G991-1 & G671-2 & G727-2 \\
\hline \multirow{2}{*}{ Chemistry } & $\mathrm{P}($ wt.\%) & $<0.001$ & 0.008 & 0.022 & $<0.001$ & 0.022 & 0.022 \\
\cline { 2 - 8 } & $\mathrm{B}$ (wt.\%) & $<0.001$ & 0.004 & $<0.001$ & 0.013 & 0.004 & 0.011 \\
\hline \multirow{2}{*}{$\begin{array}{c}\text { S/R } \\
\text { Life } \\
\text { (Hrs.) }\end{array}$} & $\begin{array}{c}649 \mathrm{C} / \\
669 \mathrm{MPa}\end{array}$ & 19.5 & 208 & 242 & 73 & 523 & 704 \\
\cline { 2 - 8 } & $\begin{array}{c}649^{\circ} \mathrm{C} / \\
773 \mathrm{MPa}\end{array}$ & 6.0 & 57 & 63 & 24 & 125 & 155 \\
\hline
\end{tabular}




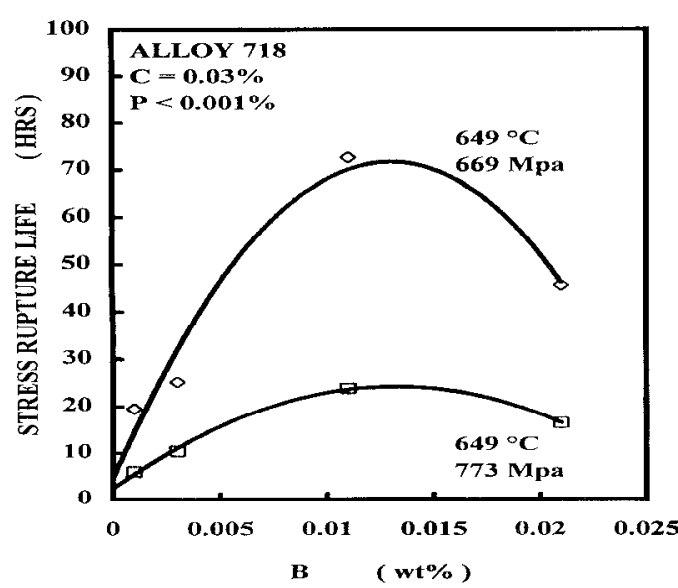

Figure 3 - Effect of $B$ level on stress rupture life of Alloy 718 with very low $\mathrm{P}$ level.

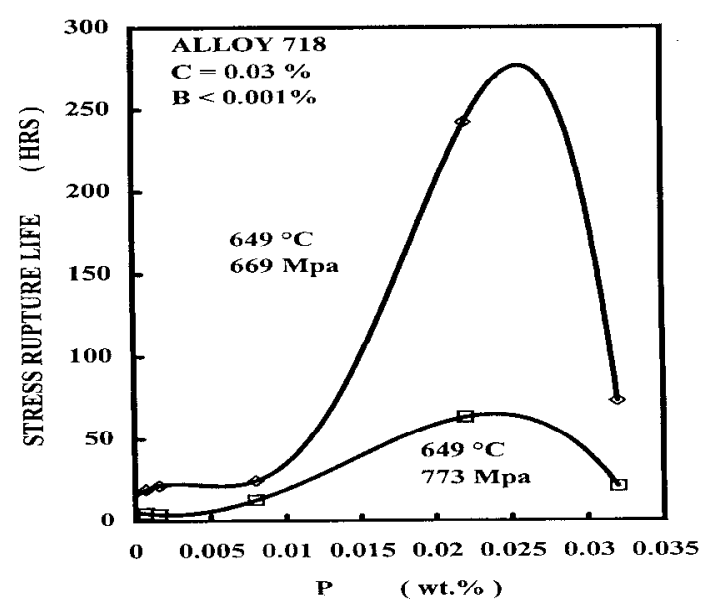

Figure 4 - Effect of P level on stress rupture life of Alloy 718 with very low $B$ level.

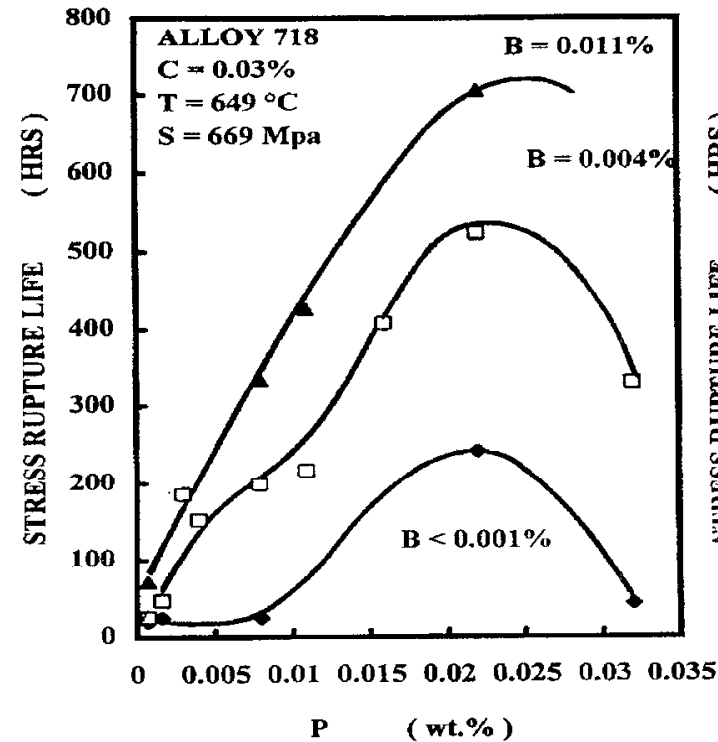

(a)

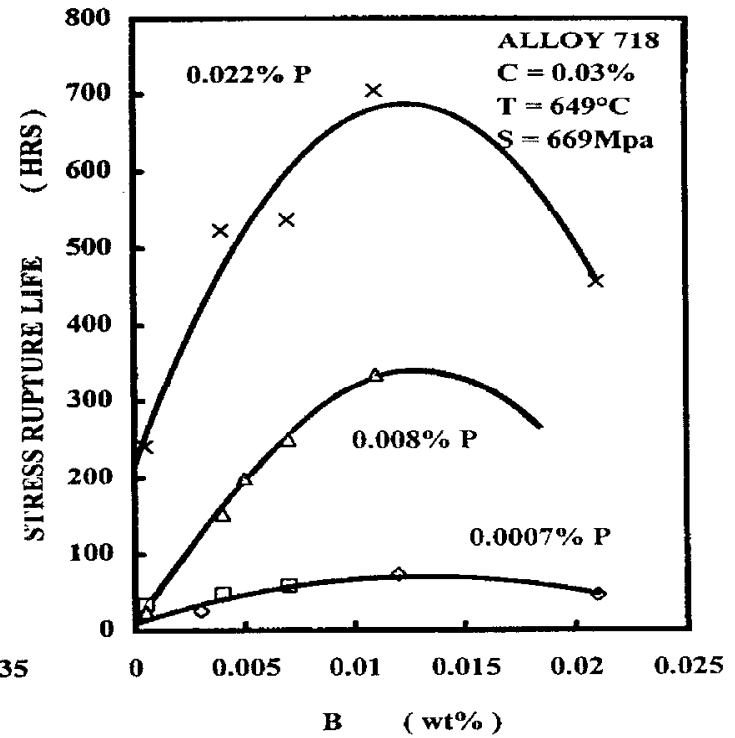

(b)

Figure 5 - Stress rupture life of Alloy 718 as a function of (a) P and (b) B levels.

It can be seen that the stress rupture life of very "pure" alloy (G988-2) is very low, and life increases by raising $\mathrm{P}$ or $\mathrm{B}$ with $\mathrm{P}$ having a greater effect. The stress rupture life of commercial 718 (nominally alloys with $0.004-0.008 \% \mathrm{P}$ and $0.003-0.005 \% \mathrm{~B}$, such as $\mathrm{G} 500-1$ ) is almost one order of magnitude higher than that of the "pure" alloy, but stress rupture life is further increased by increasing $\mathrm{P}$ and $\mathrm{B}$ contents. In comparison to the commercial alloy, stress rupture life of the alloy with optimum $P$ and B levels (G727-2) is increased by approximately three times. 
Stress rupture ductility does not appear to be adversely affected by increasing $\mathrm{P}$ and $\mathrm{B}$ levels. Normally, ductility for test alloys with increased $\mathrm{P}$ and $\mathrm{B}$ levels was similar to, or sometimes better than, that of alloys of the commercial composition.

\section{Microstructure and Resistance to Thermal Softening}

The microstructures viewed optically and by SEM did not change noticeably with $\mathrm{P}$ and $\mathrm{B}$ contents, see Figure 6 . The grain size was within the range of $7 \pm 1 \mu \mathrm{m}$. The volume fraction, size and distribution of $\delta$ phase were also very similar among the test alloys and did not change noticeably during stress rupture tests. All these facts imply that the improvements in stress rupture properties by $\mathrm{P}$ and $\mathrm{B}$ modification are not due to changes in microstructural features at the resolution level of the optical microscope or SEM.

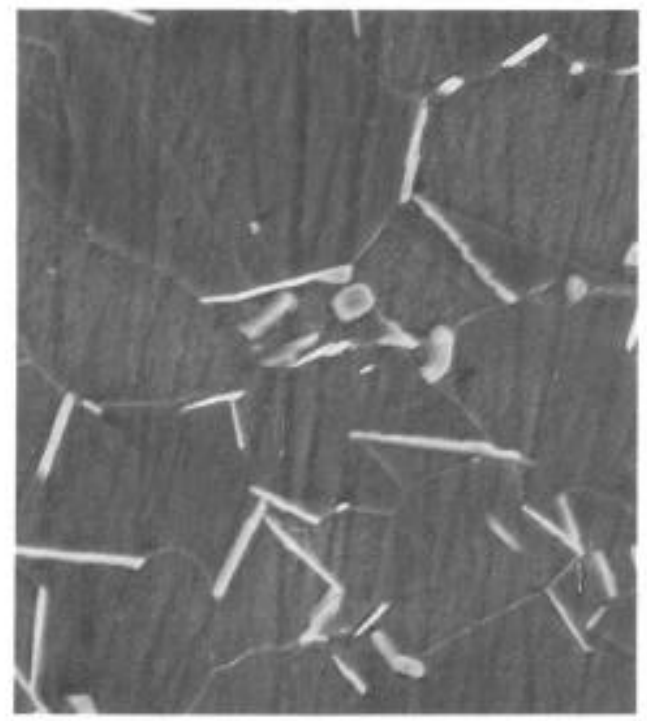

(a)

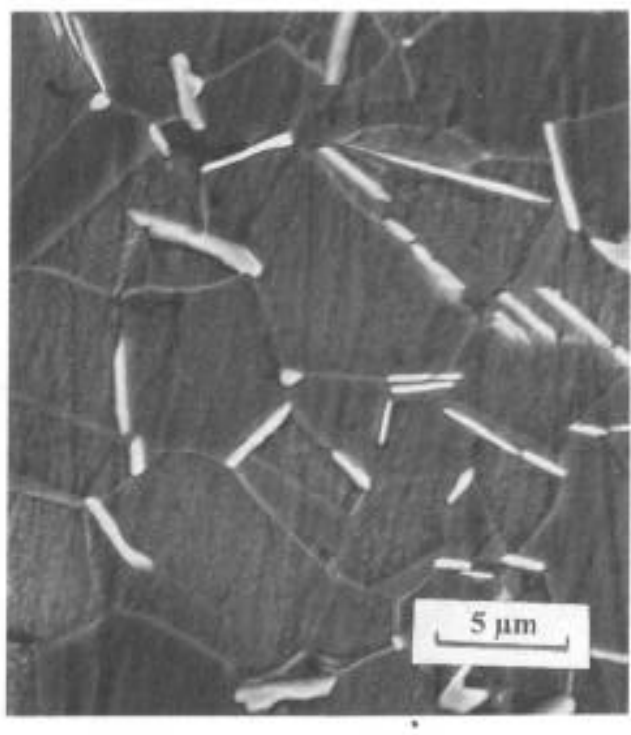

(b)

Figure 6 - SEM microstructure in (a) pure test alloy 718 with very low $\mathrm{P}$ and $\mathrm{B}$ and (b) modified alloy 718 with optimum $\mathrm{P}$ and $\mathrm{B}$.

Much higher hardness was shown in interrupted test specimens of alloys with increased $\mathrm{P}$ and $\mathrm{B}$ contents in comparison with that of the commercial alloy. For example, the HV hardness of the commercial alloy and the alloy with optimum P and B contents were virtually identical (HV $478 \mathrm{vs}$. HV 476) prior to testing, but the hardness of the commercial alloy dropped to HV 455 after a $32 \mathrm{hr}$ test at $649^{\circ} \mathrm{C} / 773 \mathrm{MPa}$, while the hardness was only reduced to HV 472 for the P and B modified alloy after a $36 \mathrm{hr}$ test at exactly the same test conditions. Although test times are short, this suggests that the increased $\mathrm{P}$ and $\mathrm{B}$ significantly raised the resistance of alloy 718 to thermal softening (over aging).

\section{Fractography}

The fracture modes with different $\mathrm{P}$ and $\mathrm{B}$ levels can be divided into two categories. In one category, the failure started with intergranular cracking, and the specimen broke with ductile dimple fracture after a certain degree of intergranular crack propagation. Completely trans- 
granular fracture was found in the other category, and specimens failed with $100 \%$ ductile dimple fracture.

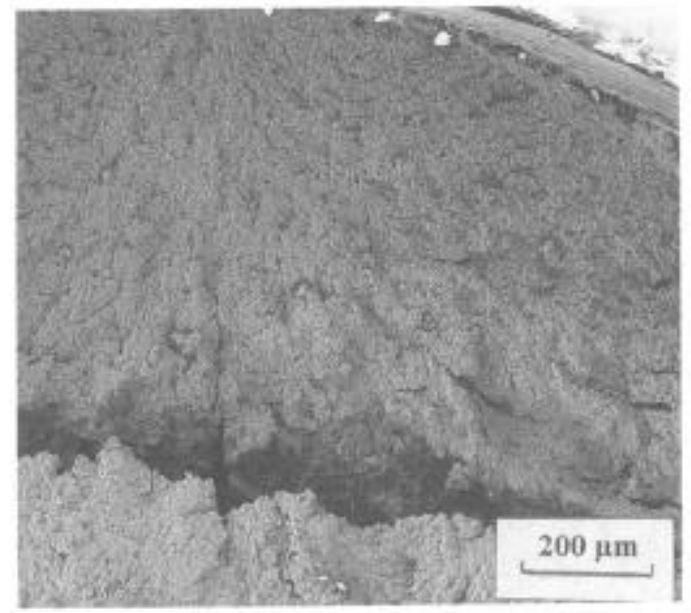

(a)

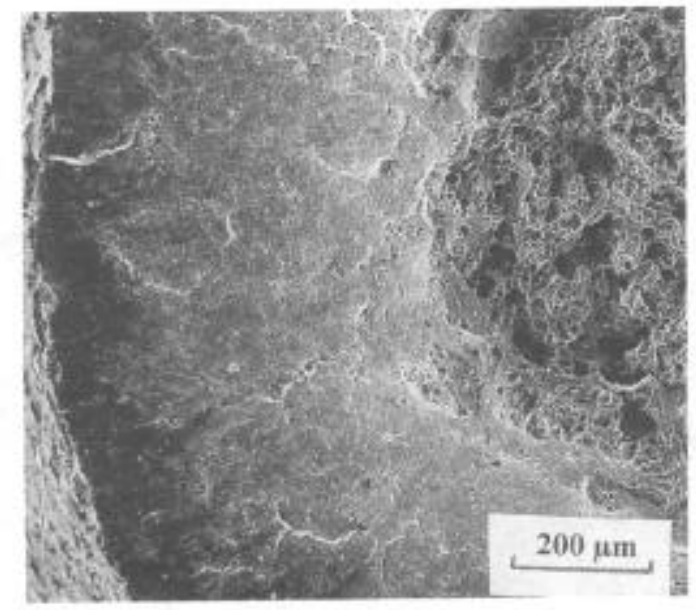

(c)

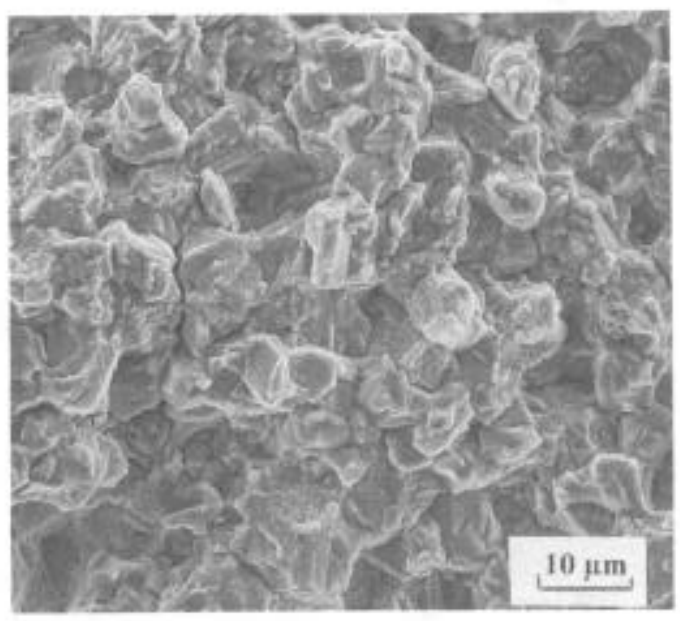

(b)

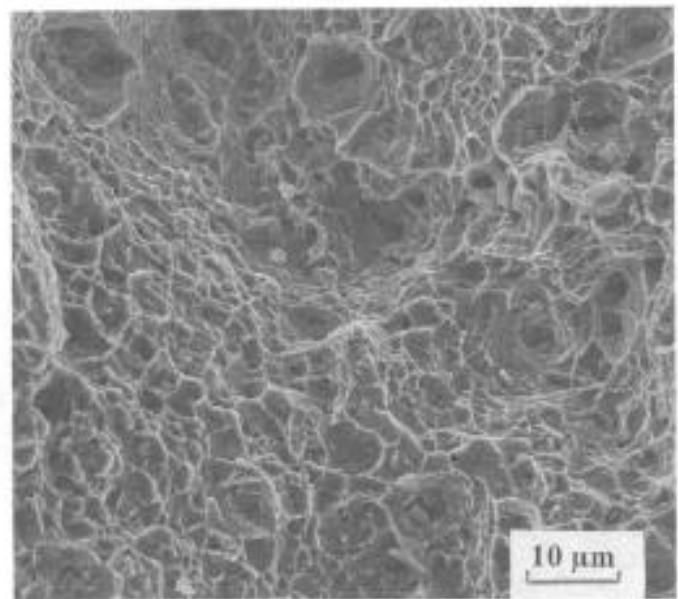

(d)

Figure 7 - Creep fracture modes of (a) and (b) Pure test alloy 718 with very low P and B and (c) and (d) Modified alloys with optimum P and B levels.

The typical morphologies of these two types of fracture modes are shown in Figure 7. On the basis of SEM fractographic results, it is possible to construct a map of fracture mode to demonstrate the effect of $\mathrm{P}$ and $\mathrm{B}$ additions on the fracture mode of alloy 718, as shown in Figure 8. It can be seen from this figure that the fracture mode in a "pure" alloy with very low P and B levels is intergranular, and adding $\mathrm{P}$ or $\mathrm{B}$, or both, reduces the tendency to intergranular separation. The intergranular cracking is basically eliminated in commercial alloys, and entirely transgranular dimple fracture is also seen in alloys with high $\mathrm{P}$ and $\mathrm{B}$ additions. It is worth noting that the $\mathrm{B}$ addition, up to the highest level used in this study $(0.024 \%)$, did not completely eliminate the intergranular separation at very low $\mathrm{P}$ levels, but the $\mathrm{P}$ addition by itself did as long as its level was higher than about $0.008 \%$. 


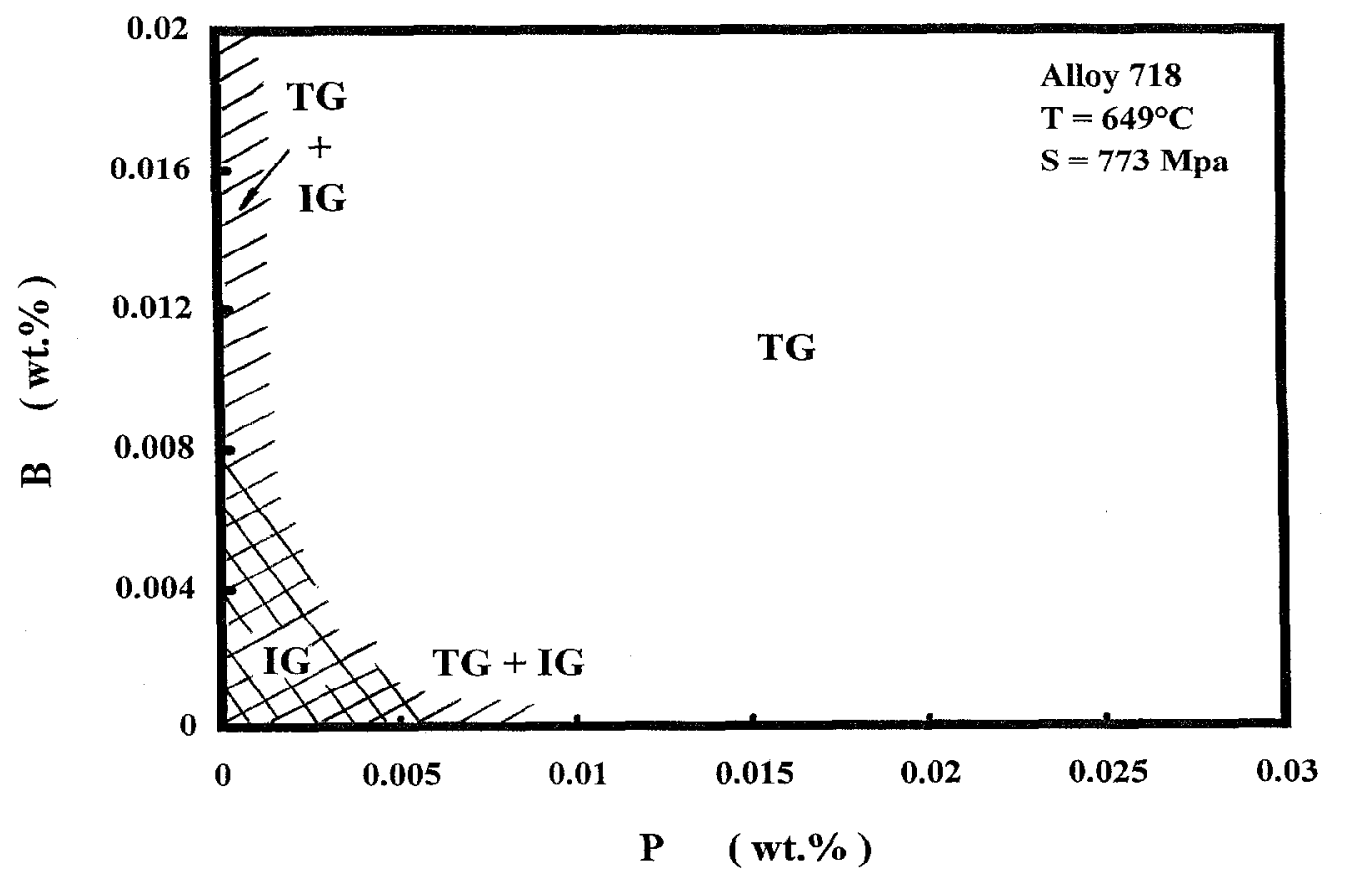

Figure 8 - Map of stress rupture fracture modes in Alloy 718 as a function of $\mathrm{P}$ and $\mathrm{B}$ levels. TG - Transgranular Dimple Fracture, IG - Intergranular Fracture, TG + IG - TG in some specimens and IG in other specimens.

\section{Discussion}

This study clearly shows that both $\mathrm{P}$ and $\mathrm{B}$ enhance the resistance of alloy 718 to creep deformation, and that there is a synergistic interaction between these two elements. To fully characterize the effect of $\mathrm{P}$ and $\mathrm{B}$, a phenomenological description of $\mathrm{P}$ and $\mathrm{B}$ effects can be developed.

Mathematically, the inherent effect of $\mathrm{P}$ or $\mathrm{B}$ on stress rupture life time of alloy 718 can be described by an equation with the following form:

$$
\left.\mathrm{t}_{\mathrm{f}}^{\mathrm{i}}=\mathrm{t}_{\mathrm{fo}}{ }^{\mathrm{i}} \exp \left\{-\mathrm{A}_{\mathrm{i}}\left(\mathrm{I}-\mathrm{a}_{\mathrm{i}}\right)^{2}\right]\right\}
$$

where $\mathrm{i}$ denotes the element $\mathrm{P}$ or $\mathrm{B}, \mathrm{t}_{\mathrm{f}}^{\mathrm{i}}$ is stress rupture life of an alloy containing $i, \mathrm{t}_{\mathrm{fo}}{ }^{i}$ the maximum stress rupture life, $A$ is a proportional cocfficient, $I$ is the weight percent of the content of the element $\mathrm{i}$ ( $\mathrm{P}$ or $\mathrm{B}$ ), and $\mathrm{a}_{\mathrm{i}}$ the weight percent of the element $\mathrm{i}$ at which stress rupture life reaches the maximum.

The combined effect of P and B can be described by:

$$
t_{f}^{P, B}=t_{f 0}^{P, B} \exp \left\{-A_{P}\left(P-a_{P}\right)^{2}\right\} \exp \left\{-A_{B}\left(B-a_{B}\right)^{2}\right\}
$$

where $t_{f 0}{ }^{P, B}$ is the maximum achievable stress rupture life reached at $P=a_{P}$ and $B=a_{B}$. The effect of $P$ and $B$ can be seen from their influence on the coefficients $A_{P}$ or $A_{B}$ which reflect 
the rate of increase in stress rupture life with increasing $\mathrm{P}$ or $\mathrm{B}$ level. The experimental results from this study suggest that $A_{P}$ is greater than $A_{B}$ by a factor of 1.5 to 2 , and that $A_{P}$ and $A_{B}$ are each affected by the presence of both $B$ and $P$, i.e. the synergistic effect.

The mechanisms responsible for the changes in creep deformation resistance caused by $\mathrm{P}$ and $\mathrm{B}$ are not yet clear and remain under study. However, some tentative suggestions have been provided from this work. One mechanism would be that of increased grain boundary cohesion due to $\mathrm{P}$ and $\mathrm{B}$ additions. As shown in the fractographic study, $\mathrm{P}$ and $\mathrm{B}$ drastically suppressed the occurrence of intergranular fracture which is most likely controlled by grain boundary cohesion. Phosphorus appears to exert a stronger effect in this regard. This is completely different from the well-known situation in BCC iron alloys where P significantly weakens grain boundary cohesion. This is also contradictory to some theoretical work ${ }^{4}$ which predicted a reduction in grain boundary cohesion by $\mathrm{P}$ addition to Ni. However, there is some evidence, ${ }^{5,6}$ to show an increase in grain boundary cohesion in Ni-Cr-Fe alloys due to increased $\mathrm{P}$. Nevertheless, more experimental and theoretical work should be done to further evaluate the relative effect of $\mathrm{P}$ and $\mathrm{B}$ in strengthening grain boundaries of alloy 718 and to clarify the detailed mechanisms. In addition, the strength of the grain boundaries (intergranular fracture) appears to be a factor in stress rupture life only at very low $\mathrm{P}$ and $\mathrm{B}$ levels and cannot explain the difference in properties between nominal commercial and optimum $\mathrm{P}$ and $\mathrm{B}$ level alloys.

Another possible mechanism would involve the effect of $\mathrm{P}$ and $\mathrm{B}$ on transgranular dislocation climb, which is most likely the controlling creep mechanism in commercial and P-B modified alloy 718. There are a number of possible mechanisms through which $\mathrm{P}$ and $\mathrm{B}$ can retard dislocation climb; namely, direct elastic interaction between dislocations and $\mathrm{P}$ and $\mathrm{B}$ atoms in solution, precipitation hardening by phosphide and boride particles and reduction of $\gamma^{\prime \prime}$ particle growth by interface segregation of $\mathrm{P}$ and $\mathrm{B}$ atoms or by the interaction between vacancies and $\mathrm{P}$ and $\mathrm{B}$ atoms. Work done at ORNL ${ }^{7.8}$ has found an insufficient number density of phosphoride or boride particles to cause the observed change, and no preferred segregation at the $\gamma^{\prime}$ or $\gamma^{\prime \prime}$ particle-matrix interfaces. Thus, the most likely mechanism appears to be vacancy and dislocation $-\mathrm{P}$ and $\mathrm{B}$ atom interaction, which would reduce the migration rate of dislocations and vacancies. The reduced vacancy migration rate could lead to the reduction of $\gamma$ " particle growth, leading to a higher resistance to dislocation movement. However, no significant difference in $\gamma^{\prime \prime}$ particle growth behavior was found ${ }^{8}$ in alloys with different $\mathrm{P}$ and $\mathrm{B}$ levels. More detailed results of the effect of $\mathrm{P}$ and $\mathrm{B}$ on $\gamma^{\prime \prime}$ particle growth will be published elsewhere ${ }^{9}$. The rate of dislocation climb could also be reduced by lowering the migration rate of vacancies and by some dislocation pinning mechanisms by $\mathrm{P}$ and $\mathrm{B}$ atoms. All these effects will cause improved stress rupture life, i.e. higher resistance to creep deformation.

At this time the reasons for a synergistic effect between $\mathrm{P}$ and $\mathrm{B}$ additions are not clear.

\section{Conclusions}

The following conclusions can be drawn from this study:

1. Both $\mathrm{P}$ and $\mathrm{B}$ can increase the resistance of alloy 718 to creep deformation, leading to a higher stress rupture life, with $\mathrm{P}$ being the stronger strengthening element.

2. There is a synergistic interaction between $\mathrm{P}$ and $\mathrm{B}$ additions, i.e., the effect of a combined addition of $\mathrm{P}$ and $\mathrm{B}$ is greater than the sum of the respective effects of $\mathrm{P}$ and $\mathrm{B}$ acting independently. 
3. More than one order of magnitude improvement in stress rupture life can be achieved over the entire $\mathrm{P}$ and $\mathrm{B}$ ranges investigated. The stress rupture life of nominal commercial alloys is increased by about $300 \%$ for a modified alloy with optimum $\mathrm{P}$ and $\mathrm{B}$ contents.

4. The creep fracture mode changes from intergranular separation in pure alloys with very low $\mathrm{P}$ and $\mathrm{B}$ levels to transgranular dimple fracture in alloys with high $\mathrm{P}$ or $\mathrm{B}$, or their combination, indicating that both $\mathrm{P}$ and $\mathrm{B}$ increase the grain boundary cohesion of alloy 718 . In this respect, it appears that $P$ has a stronger effect. Increased grain boundary cohesion can be one of the mechanisms responsible for improved stress rupture life in $\mathrm{P}-\mathrm{B}$ modified alloy 718 .

5. In comparison with commercial alloys, the improved stress rupture life of alloys with high $\mathrm{P}$ and $\mathrm{B}$ contents is mainly the resull of increased resistance to transgranular dislocation climb. The mechanism for reduced dislocation climb is most likely the lower vacancy migration rate and dislocation pinning caused by the interaction with $\mathrm{P}$ and $\mathrm{B}$ atoms.

\section{References}

1. W. D. Cao and R. L. Kennedy, Superalloys $718,625,706$ and Various Derivatives, E. R. Loria, ed., TMS, (1994), p. 463.

2. W. D. Cao and R. L. Kennedy, Superalloys 1996" R. D. Kissinger et Al., eds., TMS, (1996), p. 589.

3. R. L. Kennedy, W. D. Cao and W. M. Thomas, Advanced Materials \& Processes, vol. 150, No. 3, p. 33.

4. M. Seah, Acta Metall., vol. 28, 1980, p. 955.

5. G. S. Was, J. K. Sung and T.M. Angeliu, Met Trans. A, vol. 23A, 1992, p. 3343.

6. J. K. Sung and G. S. Was, Corrosion, vol. 47, 1991, p. 824.

7. M. K. Miller, J. A. Horton, W. D. Cao and R. L. Kennedy, J. DE PHYSIQUE, IV, Vol. 6, 1996, C5-241.

8. J. A. Horton, M. K. Miller, W. D. Cao and R. L. Kennedy in Superalloys 718, 625, 706 and Various Derivatives, E. R. Loria, ed., TMS, (1997).

9. C. T. Liu, J. A. Horton, W. D. Cao and R. L. Kennedy, "Aging Studies on Tensile Properties of Microalloyed IN-718," unpublished work, to be submitted to Scripta Materialia. 